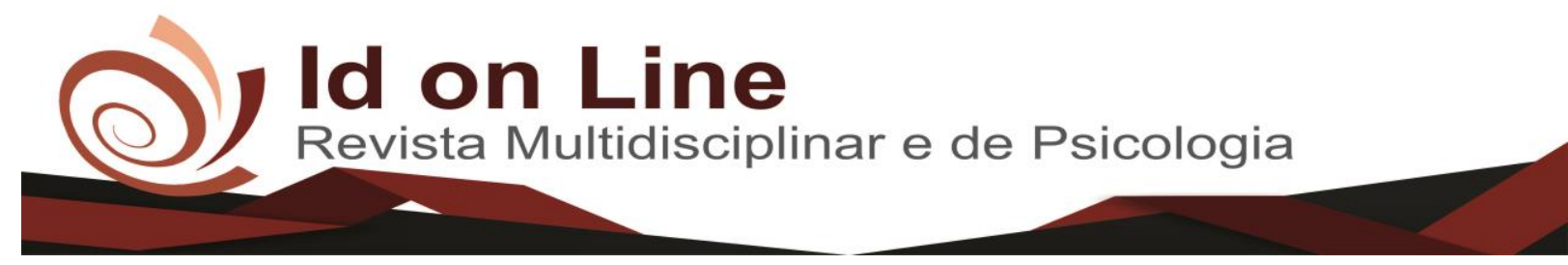

Artigo

\title{
A Importância da Contabilidade Gerencial para Microempresas e Empresa de Pequeno Porte
}

\author{
Rosa Amélia Carvalho Morais ${ }^{1}$; Agenor Campos Barreto Júnior ${ }^{2}$
}

Resumo: Este estudo descreve a contabilidade gerencial como ferramenta indispensável à tomada de decisão, explicando com detalhes o funcionamento do Balanço patrimonial, a demonstração do resultado do exercício e a demonstração do fluxo de caixa. Assim, por intermédio do uso desses instrumentos da contabilidade, pode-se elaborar instrumentos indispensáveis para o gestor gerencial da organização. $\mathrm{O}$ trabalho apresenta modelos de Balanço Patrimonial, Demonstração do Resultado do Exercício e de Fluxo de Caixa. Utilizou-se como metodologia a pesquisa bibliográfica descritiva, como melhor recurso para explicar a contabilidade gerencial. Como resultado, pode-se dizer que as ferramentas da contabilidade usadas na contabilidade gerencial são recursos indispensáveis para a tomada de decisão do gestor, pois foi permitido verificar que o uso dos padrões contábeis possibilitam mitigar erros e falhas nos processos encontrados nas empresas, favorecendo assim, a retificação de erros para a tomada de decisão.

Palavras - Chave. Contabilidade gerencial. Modelos contábeis. Tomada de decisão. Empresas.

\section{The Importance of Management Accounting for Micro and Small Companies}

\begin{abstract}
This study describes managerial accounting as an indispensable tool for decision making, explaining in detail the functioning of the balance sheet, the statement of income for the year and the statement of cash flow. Thus, through the use of these accounting instruments, it is possible to elaborate indispensable tools for the managerial manager of the organization. The work presents models of balance sheet, statement of income for the year and cash flow. Descriptive bibliographic research was used as methodology, as the best resource to explain management accounting. As a result, it can be said that the accounting tools used in managerial accounting are indispensable resources for the manager's decision making, since it was possible to verify that the use of the accounting standards make it possible to mitigate errors and failures in the processes found in the companies, thus favoring, the rectification of errors for decision making.
\end{abstract}

Keywords. Management accounting. Accounting models. Decision making. Companies

\section{Introdução}

Uma empresa para se estruturar de maneira adequada, correta e competitiva é preciso que faça uso adequado do desenvolvimento de processos de planejamento e de estratégias, só

\footnotetext{
${ }^{1}$ Centro Universitário Doutor Leão Sampaio - UNILEÃO. rosinha18dez@icloud.com;

${ }^{2}$ Graduação em Ciências Contábeis pela Universidade Estadual Vale do Acaraú, Especialista em Auditoria e Controladoria, Especialista em Gestão Tributária pela Faculdade Leão Sampaio, Mestrando em Contabilidade pela FUCAPE - Business School.
} 
assim é possível identificar a sua posição no mercado aonde está atuando. Dessa forma, o seu setor gerencial poderá avaliar melhor os tipos de decisões que precisam ser tomadas para alcançar os objetivos traçados, maximizando seus lucros e resultados.

Dentro do mercado competitivo, uma organização, não importa o tamanho, mal estruturada e sem visão de seus acontecimentos contábeis, torna-se um alvo fácil e vulnerável para o mercado que está em constante competição. De outro modo, a instituição deverá tomar todas as medidas indicadas pelas ciências contábeis, para favorecer o seu processo de gestão. Assim, o entendimento objetivo das informações contábeis poderá capacitar a situação financeira de uma entidade, pois dados do balanço patrimonial bem avaliados mostra o grau de risco de uma decisão a ser tomada.

Sendo assim, utiliza-se a contabilidade gerencial, como ferramenta que avalia os processos de planejamento e controle, voltada para dar suporte aos gerentes e executivos em todas as etapas que levam a decisões. Drucker (2010) apud Amorim (s/d, p.3):

\begin{abstract}
Bons tomadores de decisões não tomam muitas decisões. Eles tomam decisões que fazem a diferença. E eles sabem quando uma decisão e necessária. E então eles não adiam. Bons tomadores de decisões sabem que a parte mais importante, e mais difícil, da tomada de decisões não é tomar a decisão. Isso costuma ser bem fácil. A parte mais difícil e mais importante e certificar-se de que a decisão tem a ver com o problema certo. Poucas coisas são mais prejudiciais do que tomar decisões certas a respeito do problema errado.
\end{abstract}

Para lidar com essas ameaças, o gestor deve tomar decisões, selecionando uma solução a partir de um rol de alternativas.

De acordo com Frezatti et al (2007), o sistema de informações contábeis está dividido em dois subsistemas: o financeiro e o gerencial, não precisam ser independentes, mas devem ser integrados, pois os mesmos precisam estar ligados com a base de dados contábeis, onde a saída de um dos dois poderá ser a entrada no outro. Enfim, autores como Hansen e Mowen (2000) apud Frezatti et al (2007) defendem a integração da base de dados contábil no processo de gestão.

Assim, diante desse ambiente integrado, a tomada de decisão se torna eficiente. Desse modo, a contabilidade gerencial surge como importante elemento no processo, pois ela é fonte de grandes informações para o planejamento da empresa. De conformidade com Horngren, Foster e Datar (2000) apud Frezatti et al (2017), a contabilidade gerencial facilita o planejamento, o controle, fornecendo informações sobre: representação financeira de planos e orçamentos; registro de classificações contábeis; e a comparação entre o que foi orçado e o real. 
Mas para que esse processo funcione, a contabilidade gerencial deverá se valer das ferramentas contábeis, como as demonstrações contábeis: Balanço patrimonial, Demonstração dos resultados do exercício e demonstração do fluxo de caixa.

Assim, torna-se relevante refletir sobre a utilização das demonstrações contábeis nas empresas, analisando o Balanço Patrimonial, a demonstração do resultado do exercício e a demonstração do fluxo de caixa de ferramentas da contabilidade gerencial.

\section{Revisão de Literatura}

\section{Breves Apontamentos sobre Empresas}

A profissão contábil vive hoje profundas transformações, principalmente no trabalho que desenvolve nas empresas em geral. No ambiente empresarial atual, as empresas passam a ter informações mais consistentes, confiáveis e transparentes. Assim, as informações mediante um sistema contábil organizado, em especial aquelas extraídas das demonstrações contábeis passaram a serrem úteis à gestão empresarial (CAETANO, s/d).

Então, o que é uma empresa? Conforme Sales (2007), há três significados jurídicos para o vocábulo técnico de empresa, que correspondente aos três primeiros perfis sobre o significado de empresa: Perfil subjetivo. A empresa é o empresário, pois empresário é quem exercita a atividade econômica organizada, de forma continuada. Nesse sentido, a empresa pode ser uma pessoa física ou uma pessoa jurídica, pois ela é titular de direitos e obrigações; Perfil funcional. A empresa é uma atividade, que realiza produção e circulação de bens e serviços, mediante organização de fatores de produção (capital, trabalho, matéria prima; Perfil objetivo (patrimonial). A empresa é um conjunto de bens. A palavra empresa é sinônima da expressão estabelecimento comercial. Os bens estão unidos para uma atividade específica, que é o exercício da atividade econômica. Como exemplo desse significado, podemos dizer a mercadoria saiu ontem da empresa.

Há grandes, médias, pequenas e empresas de pequeno porte, além de microempresas. As empresas de pequeno porte e as microempresas, por serem de capital menor, necessitam serem protegidas, assim, a Lei complementar n. 123, de 14 de dezembro de 2006 criou o Estatuto da Microempresa e da Empresa de Pequeno Porte, sendo posteriormente alterada pela Lei Complementar n. 128/2008. Esta lei considera microempresas e empresas de pequeno porte a sociedade empresária, a sociedade simples e o empresário devidamente registrados no 
Registro de Empresas Mercantis ou no Registro Civil de Pessoas Jurídicas (art. 966 da Lei n. 10.406, de 10 de janeiro de 2002). De acordo com essa Lei, essas empresas deverão estar de acordo com a receita bruta. Ver quadro 1.

Quadro 1 - Classificação das microempresas e empresas de pequeno porte conforme o faturamento bruto anual em relação ao simples nacional e às exportações

\begin{tabular}{|c|c|c|}
\hline $\begin{array}{l}\text { QUANTO A CATEGORIA DE } \\
\text { IMPOSTO DE RENDA E DE } \\
\text { ATIVIDADE }\end{array}$ & $\begin{array}{c}\text { MICROEMPRESAS - } \\
\text { FATURAMENTO BRUTO } \\
\text { ANUAL }(\mathbf{R} \$)\end{array}$ & $\begin{array}{c}\text { EMPRESAS DE PEQUENO } \\
\text { PORTE - FATURAMENTO } \\
\text { BRUTO ANUAL (R\$) }\end{array}$ \\
\hline \multirow[t]{2}{*}{ Simples } & Até 240 mil & $\begin{array}{l}\text { Maior que } 240 \text { mil e menor que } \\
2,4 \text { milhões }\end{array}$ \\
\hline & $\begin{array}{l}\text { Microempresas - faturamento } \\
\text { bruto anual (US\$) }\end{array}$ & $\begin{array}{l}\text { Empresas de pequeno porte - } \\
\text { faturamento bruto anual (US\$) }\end{array}$ \\
\hline Exportações & $\begin{array}{c}\text { Até } 200 \text { mil para comércio e } \\
\text { serviços - Até } 400 \text { mil na indústria }\end{array}$ & $\begin{array}{c}\text { Acima de } 200 \text { mil e até } 1,5 \\
\text { milhões para comércio e serviços } \\
\text { - E acima de } 400 \text { mil até } 3,5 \\
\text { milhões na indústria }\end{array}$ \\
\hline
\end{tabular}

Fonte: Sebrae (2011)

O Sebrae utiliza o conceito de número de funcionários na empresa para a definição do porte. Para a Microempresa na indústria e construção até 19 funcionários, e no comércio e serviços até 09 funcionários. Já a Pequena Empresa na indústria e construção, de 20 a 99 funcionários, e no comércio e serviços, de 10 a 49 funcionários (SEBRAE. 2011). Veja o quadro 2.

Quadro 2 - Classificação de Micro e Empresa de Pequeno Porte conforme o número de funcionários.

\begin{tabular}{|l|c|c|}
\hline \multirow{2}{*}{\multicolumn{1}{c|}{ Setor }} & \multicolumn{2}{c|}{ FUNCIONARIOS } \\
\cline { 2 - 3 } & Microempresa & Empresa Pequeno Porte \\
\hline Indústria e Construção Civil & Até 19 funcionários & 20 a 99 funcionários, \\
\hline Comércio & Até 09 funcionários & 10 a 49 funcionários \\
\hline Serviço & Até 09 funcionários & 10 a 49 funcionários \\
\hline
\end{tabular}

Fonte: Sebrae (2011).

\section{Uso da Contabilidade nas Empresas}

Para Iudícibus (2010) citado por Bampi e Silva (2018, p.4), a aplicação da Contabilidade tem como objetivo fornecer aos empresários informações sobre aspectos de natureza econômica, financeira e física do patrimônio de sua instituição, fazendo registros, demonstrações, análises, diagnósticos e prognósticos expressos sob forma de relatos, pareceres, tabelas, planilhas e outros meios. Assim, tendo como base essas informações, pode-se dizer que a contabilidade é uma fonte de ferramentas no processo de mutações do patrimônio, ou seja, os fatos que já aconteceram. 
Entretanto, os meios da contabilidade são imensos, podendo esta ciência ser utilizada no processo de gestão de empresas, munindo os gestores das empresas, bem como das pequenas empresas para tomar decisões coesas e de acordo com suas reais condições, atuando no controle de Contas a Receber, Contas a Pagar, Fluxo de Caixa, Orçamento. Para isso, a contabilidade gerencial se torna uma ferramenta mestra no processo.

Desse modo, o presente capítulo buscará entender como a contabilidade gerencial pode ser utilizada nas empresas e quais as ferramentas que ela utiliza nos processos de controle das atividades e movimentações de mercadorias e valores.

\title{
Contabilidade Gerencial
}

Antes de mostrar a contabilidade gerencial, é importante a definição do trabalho do gerente. Conforme Junquilho (2001, p.6):

\begin{abstract}
O trabalho gerencial, de acordo com os primeiros estudos clássicos sobre o tema (FAYOL, 1970, GULICK, 1937), vem sendo descrito como composto de uma série de funções básicas. Em FAYOL (1970), são definidas as conhecidas funções administrativas: planejar, coordenar, controlar, comandar e organizar. Em GULICK (1937), elas são reforçadas e ampliadas por aquilo que ele denominou ser a essência do trabalho gerencial: o POSDCORB, isto é, planejamento, organização, assessoramento ("staffing"), direção, coordenação, informação ("reporting") controle contábil-financeiro ("budgeting").
\end{abstract}

Embora outros conceitos tenham sido colocados através da história da administração, a organização depende de um assessoramento com informações de controle contábil-financeiro para a tomada de decisão. Este controle contábil-financeiro dará suporte à contabilidade gerencial. Assim, a administração de empresas necessita de uma ferramenta indispensável para gerir a sua contabilidade, esta ferramenta é a contabilidade gerencial. Esta está voltada de forma exclusiva pra a administração empresarial. De acordo com Iudícibus (1995, p.21):

\begin{abstract}
A contabilidade gerencial num sentido mais profundo, está voltada única e exclusivamente para a administração da empresa, procurando suprir informações que se 'encaixem' de maneira válida e efetiva no modelo decisório do administrador". (IUDÍCIBUS, 1995, p.21).
\end{abstract}

Crepaldi (2008) complementa esta definição quando diz que a contabilidade gerencial fornece instrumentos aos administradores de empresas: 
gerenciais. É voltada para a melhor utilização dos recursos econômicos da empresa, através de um adequado controle dos insumos efetuado por um sistema de informação gerencial (CREPALDI, 2008, p.5.)

De forma mais específica, esses instrumentos da contabilidade gerencial auxilia os gerentes em sua administração financeira, dentro do processo de gestão, sabendo que "A contabilidade gerencial congrega todos os demais instrumentos de contabilidade que complementam a contabilidade financeira para tornar efetiva a informação contábil dentro das empresas em todos os processos de gestão"

A contabilidade gerencial congrega elementos que complementam a contabilidade financeira, caracterizando-se como um enfoque especial, contribuindo com técnicas e procedimentos contábeis conhecidos e tratados na contabilidade financeira, na contabilidade de custos, na análise financeira, de balanços e outras ferramentas. Dentro de uma perspectiva diferente, num grau mais detalhado e analítico, a contabilidade gerencial auxilia os gerentes na tomada de decisão.

A contabilidade gerencial pode ser caracterizada superficialmente, como um enfoque especial conferido a várias técnicas e procedimentos contábeis já conhecidos e tratados na contabilidade financeira, na contabilidade de custos, na análise financeira e de balanços etc., colocados numa perspectiva diferente, num grau de detalhe mais analítico ou numa forma de apresentação e classificação diferenciada, de maneira a auxiliar os gerentes das unidades em seu processo decisório (IUDICIBUS, 2005).

Vale salientar, que, conforme Padoveze (2012), a contabilidade gerencial tem como foco o processo de tomada de decisão dos usuários internos. Ela procura de certo modo atender todos os profissionais dentro da empresa. Isso em qualquer nível de hierarquia, importando apenas que haja a necessidade de informação contábil para a tomada de decisão.

Desse modo, numa comparação entre a contabilidade gerencial e a contabilidade financeira, pode-se dizer a que contabilidade gerencial e mais analítica, mais detalhada que a contabilidade financeira. Conforme Padoveze (2012), a contabilidade financeira procura mostrar seus relatórios para os usuários externos em relatórios formatos sintéticos. Isso com grandes numerações, valores. Um exemplo prático é o balanço patrimonial. Enquanto isso, a contabilidade gerencial alimenta-se de informações existentes na contabilidade financeira, realizando complementos necessários para os gestores internos. Padoveze (2012) informa que não possui modelos específicos de relatórios, pois as informações contábeis gerenciais devem ser apresentadas em desenvolvidos para cada tomada de decisão especificamente, sendo adaptados para o perfil do usuário do relatório. 
Enfim, pelos autores citados, a contabilidade gerencial trabalha com dados da contabilidade financeira.

Padoveze (1999) indica que "A Contabilidade gerencial pode ser definida como o processo de identificação, mensuração, acumulação, análise, preparação, interpretação, e comunicação de informação...” Isso pode ser feito tanto de forma financeira como operacional, sendo usada para o planejamento, avaliação e controle no processo da organização, assegurado, assim, a responsabilidade sobre os recursos.

A contabilidade gerencial é excelente ferramenta que dá suporte â administração financeira, de forma exclusiva, fornecendo instrumentos administrativos para auxiliar gerentes. Ao mesmo tempo, usa as mesmas técnicas contábeis da contabilidade financeira, da contabilidade de custos, na análise de balanços e outras. Para Iudícibus (1995, p.21), num sentido mais abrangente, a contabilidade gerencial estaria mais voltada para a administração de empresas, suprindo informações que se encaixem nas decisões do administrador.

A contabilidade gerencial num sentido mais profundo, está voltada única e exclusivamente para a administração da empresa, procurando suprir informações que se 'encaixem' de maneira válida e efetiva no modelo decisório do administrador". (IUDÍCIBUS, citado por DAUZACKER, 2002 ,77-79)

Concordando com Iudícibus, Crepaldi (2008, p.5), reforça que a contabilidade gerencial é um ramo da contabilidade que tem por objetivo fornecer instrumentos aos administradores de empresas que os auxiliem em suas funções gerenciais.

\begin{abstract}
A contabilidade Gerencial é o ramo da contabilidade que tem por objetivo fornecer instrumentos aos administradores de empresas que os auxiliem em suas funções gerenciais. É voltada para a melhor utilização dos recursos econômicos da empresa, através de um adequado controle dos insumos efetuado por um sistema de informação gerencial" (CREPALDI citado por AMORIM, p.11).
\end{abstract}

Na sua concepção, ela está voltada para a melhor utilização de recursos econômicos das empresas, controlando adequadamente insumos, utilizando-se de um sistema de informação gerencial.

Tomando como base as definições apresentadas acima, segundo Padoveze (2012), a contabilidade gerencial apresenta aspectos fundamentais para a tomada de decisão dos usuários internos da empresa, ou melhor, ela deverá atender as pessoas dentro da empresa, independentemente do nível hierárquico, assim: “A contabilidade gerencial congrega todos os demais instrumentos de contabilidade que complementam a contabilidade financeira para tornar 
efetiva a informação contábil dentro das empresas em todos os processos de gestão" (PADOVEZE, 2012).

Contanto que estes necessitem de informações contábeis para tomarem decisões em suas respectivas áreas. Isso porque a contabilidade gerencial é mais analítica, e muito mais detalhada do que a contabilidade financeira. Observe-se que a contabilidade financeira apresenta relatórios em formatos sintéticos em grandes números, como por exemplo, o balanço patrimonial. Entretanto, a contabilidade gerencial, utiliza esse mesmo balanço, complementando e aperfeiçoando-os para uso dos gestores.

A contabilidade gerencial pode ser caracterizada superficialmente, como um enfoque especial conferido a várias técnicas e procedimentos contábeis já conhecidos e tratados na contabilidade financeira, na contabilidade de custos, na análise financeira e de balanços etc., colocados numa perspectiva diferente, num grau de detalhe mais analítico ou numa forma de apresentação e classificação diferenciada, de maneira a auxiliar os gerentes das unidades em seu processo decisório" (IUDÍCIBUS citado por Amorim, 2005, p11).

Assim, ela não tem um modelo específico de relatórios, pois suas informações contábeis são apresentadas e desenvolvidas especificamente para cada tomada de decisão, sendo adaptados conforme o perfil do usuário.

Para Atkinson et al. (2000, p.36) citado por Machado (“A informação gerencial contábil é uma das fontes informacionais primárias para a tomada de decisão e controle nas empresas.

Quadro 3 - Funções da informação Gerencial Contábil

\begin{tabular}{|c|l|}
\hline \multicolumn{2}{|c|}{ FUNÇÕES DA INFORMAÇÃO GERENCIAL CONTÁBIL } \\
\hline Controle Operacional & $\begin{array}{l}\text { Fornece informação (feedback) sobre a eficiência e a } \\
\text { qualidade das tarefas executadas. }\end{array}$ \\
\hline Custeio do produto e do cliente & $\begin{array}{l}\text { Mensura os custos dos recursos para se produzir, } \\
\text { vender e entregar um produto ou serviço aos clientes. }\end{array}$ \\
\hline Controle Administrativo & $\begin{array}{l}\text { Fornece informação sobre o desempenho financeiro e } \\
\text { competitivo de longo prazo, condições de mercado, } \\
\text { preferência dos clientes e inovaçôs tecnológicas. }\end{array}$ \\
\hline Controle estratégico & $\begin{array}{l}\text { Fornece informações sobre o desempenho financeiro e } \\
\text { competitivo de longo prazo, condições de mercado, } \\
\text { preferências dos clientes e inovações tecnológicas. }\end{array}$ \\
\hline
\end{tabular}

Fonte: Atkinson et al (2000, p 45) citado por MACHADO (s/d p.3)

Viu-se que a contabilidade gerencial toma as ferramentas da contabilidade financeira para apoiar gerentes e administradores. Mas que entre as duas contabilidades as diferenças são básicas, enquanto a contabilidade financeira é voltada para o público externo: fornecedores, 
Investidores, governo; a contabilidade gerencial atua junto ao público interno: gestores, administradores.

\section{Aplicação da contabilidade gerencial nas empresas}

O conhecimento aprofundado das ferramentas gerenciais da contabilidade facilita de forma decisiva o gestor de uma empresa. Esse administrador empresarial deverá conhecer como funciona o controle e a saída de mercadorias, valores monetários, direitos e obrigações adquiridas, colocando-o no centro da tomada de decisões (BAMPI, 2018, p.5).

Os principais controles da contabilidade são: controle de caixa, controle de contas a receber, controle do passivo, controle de imobilizados, e o controle de estoques de mercadorias.

O controle de caixa compreende a manutenção diária de valores disponíveis em contas bancárias que poderiam ser usadas de forma imediata, ou seja, saldo de conta corrente e aplicações financeiras de curto prazo. Conforme Sá (2008) citado por Bampi (2018, p.14), o caixa significa moeda e todos os valores que podem ser convertidos em moeda. Depósitos bancários, cheques seguros e aplicações de curto prazo.

Mas para a gestão financeira da empresa ser eficiente, é necessário que seja implantado o controle gerencial, isto é, tudo o que a empresa tenha a receber, como, informações sobre os créditos a receber que tenham suas origens nas operações de vendas a prazo. Tudo isso, além de informações sobre clientes, como telefone, endereço, e-mail, isto é, para facilitar o recebimento. Conforme Ribeiro (2002) citado por Bampi (2008, p.14), "contas a receber compreendem os direitos provenientes de vendas de mercadorias ou de serviços, a prazo, que normalmente são contabilizados na conta cliente ou duplicatas a receber".

Agora, a empresa deverá também ter o controle do seu passivo, ou seja, o controle sobre as obrigações que a empresa adquiriu com fornecedores de mercadorias, despesas cotidianas, impostos, taxas a pagar, salários. Enfim, tudo o que a empresa se comprometeu a pagar posteriormente. Conforme Ribeiro (2002) citado por Bampi (2008, p.15), dívidas da empresa para com terceiros (obrigações) e dívidas para com seus proprietários (Patrimônio Líquido) fazem parte do Passivo. 


\section{Controle sobre imobilizados}

Imobilizado é uma conta do Ativo não Circulante, subgrupo permanente, onde são registrados os bens destinados a manutenção da atividade da empresa, tais como edificações, máquinas e equipamentos, veículos, etc. De acordo com Assaf Neto 2002, esse subgrupo compõe-se de todos os bens e direitos que se destinam ao funcionamento normal de uma empresa.

\section{Controle de estoques de mercadorias}

Os estoques de mercadorias são compostos por mercadorias destinados a comercialização ou como matéria prima, sua composição varia conforme a natureza da entidade. De acordo com Ribeiro (2002), os estoques compreendem todas as contas que existem no balanço. Como mercadorias, produtos acabados, matéria-prima, embalagens e outros produtos e materiais a serem consumidos pelo setor de administração.

Tendo em vista o uso dessas ferramentas contábeis a contabilidade gerencial deverá fazer uso adequado das demonstrações contábeis, assunto que se verá a seguir.

\section{Demonstrações Contábeis}

Para Caetano (s/d, p.9), as demonstrações contábeis são úteis, pois, de acordo com as Normas Brasileiras de Contabilidade (NBC), elas têm o objetivo de fornecer informações aos gestores para a tomada de decisões. Elas atendem a um número diverso de usuários, seja interno ou externo, contanto, que sejam utilizadas para a tomada de decisões. "As Demonstrações Contábeis são parte integrante das informações financeiras divulgadas por uma entidade" (CAETANO, p.9). O conjunto completo de Demonstrações Contábeis inclui, o balanço patrimonial, a demonstração do resultado do exercício, a demonstração das mutações na posição financeira (demonstração dos fluxos de caixa, de resultado abrangente ou alternativa reconhecida e aceitável), a demonstração das mutações do patrimônio líquido, demonstração do valor adicionado, notas explicativas e outras demonstrações e material explicativo que são parte integrante desse conjunto devendo ser inclusas e transcritas no livro diário, completandose com as assinaturas do titular ou de representante legal da entidade e do profissional da contabilidade legalmente habilitado. Além disso, as demonstrações contábeis, conforme Caetano: 
Podem incluir divulgações sobre os riscos e incertezas que afetem a entidade e quaisquer recursos e/ou obrigações para os quais não exista obrigatoriedade de serem reconhecidos no balanço patrimonial, tais como reservas minerais. Informações sobre segmentos industriais ou geográficos e o efeito de mudanças de preços sobre a entidade podem também ser fornecidos sob a forma de dados suplementares (CAETANO, p.9).

O importante das demonstrações contábeis é fornecer informações sobre a posição financeira da empresa, dando suporte também a contabilidade gerencial.

\section{Objetivo das Demonstrações Contábeis}

As Demonstrações Contábeis, de acordo com Caetano (s/d, p.9) tem como objetivo fornecer informações sobre a posição patrimonial e financeira, o desempenho e as mudanças na posição financeira da entidade, que sejam úteis a um grande número de usuários em suas avaliações e tomadas de decisão econômica. Elas também objetivam apresentar os resultados da atuação da administração na gestão da entidade e sua capacitação na prestação de contas quanto aos recursos que lhe foram confiados. E isso tem especial relevância para a contabilidade gerencial no processo de gestão, assim, aqueles usuários que desejam avaliar a atuação ou prestação de contas da administração fazem-no com a finalidade de estar em condições de tomar decisões econômicas que podem incluir, por exemplo, manter ou vender seus investimentos na entidade, reeleger ou substituir a administração.

É importante, assim fazer uma boa análise e leitura das Demonstrações Contábeis, pois elas indicam que as informações sobre a posição patrimonial e financeira são principalmente fornecidas pelo balanço patrimonial. As informações sobre o desempenho são basicamente fornecidas na demonstração do resultado. As informações sobre as mutações na posição financeira são fornecidas nas Demonstrações Contábeis por meio de uma demonstração em separado, tal como a de fluxos de caixa, mutações do patrimônio líquido.

\section{Conjunto completo das demonstrações contábeis}

O conjunto completo de demonstrações contábeis que a entidade deve apresentar ao final de cada exercício inclui: a) balanço patrimonial (BP) ao final do período; b) demonstração do resultado do exercício (DRE); c) demonstração do resultado abrangente do período (DRA) (*); d) demonstração das mutações do patrimônio líquido (DMPL); e) demonstração dos fluxos 
de caixa do período (DFC); f) notas explicativas (NE), compreendendo um resumo das políticas contábeis significativas e outras informações explanatórias, e; g) demonstração do valor adicionado do período (DVA), conforme NBC TG 09 - Demonstração do Valor Adicionado, se exigido legalmente ou por algum órgão regulador ou mesmo se apresentada voluntariamente (aplicável obrigatoriamente às Sociedade Anônimas de capital aberto).

Quadro 4 - Resumo das demonstrações contábeis

\begin{tabular}{|c|c|c|c|}
\hline \multirow[t]{2}{*}{ DEMONSTRAÇÃO CONTÁBIL } & 'PMES & $\begin{array}{c}\text { EMPRESAS EM } \\
\text { GERAL }\end{array}$ & $\begin{array}{c}\text { AS DE } \\
\text { CAPITAL } \\
\text { ABERTO }\end{array}$ \\
\hline & \multicolumn{3}{|c|}{ Obrigatório sim ou não } \\
\hline Balanço Patrimonial & Sim & Sim & Sim \\
\hline Demonstração do Resultado do Exercício & Sim & Sim & Sim \\
\hline Demonstração do resultado abrangente & $\begin{array}{c}\text { Pode ser } \\
\text { substituída pela } \\
\text { DLPA } \\
\end{array}$ & Sim & Sim \\
\hline $\begin{array}{l}\text { Demonstração de Lucros e e prejuízos } \\
\text { acumulados (DLPA) }\end{array}$ & Facultativo & $\begin{array}{c}\text { Pode ser } \\
\text { substituída pela } \\
\text { DMPL }\end{array}$ & $\begin{array}{c}\text { Pode ser } \\
\text { substituída pela } \\
\text { DMPL }\end{array}$ \\
\hline $\begin{array}{l}\text { Demonstração das mutações do patrimônio } \\
\text { Líquido (DMPL) }\end{array}$ & $\begin{array}{c}\text { Pode ser } \\
\text { substituída pela } \\
\text { DLPA } \\
\end{array}$ & Sim & Sim \\
\hline Demonstração dos fluxos de caixa & Sim & Sim & Sim \\
\hline Demonstração do valor adicionado & Facultativo & Facultativo & Facultativo \\
\hline
\end{tabular}

Fonte: CAETANO (s/d, p.35)

Observa-se pelo quadro que o balanço patrimonial, as demonstrações do resultado do exercício e a demonstração do fluxo de caixa são obrigatórios para todas as empresas, não importando o tamanho.

\section{Balanço patrimonial}

O balanço patrimonial evidencia tudo aquilo que a entidade possuía em determinada data, geralmente no fim do exercício social, que para a maioria das empresas finda no dia 31 de dezembro de cada ano, é composto pelo ativo, passivo e patrimônio líquido, para Iudícibus (1998), o balanço patrimonial "reflete a posição das contas patrimoniais em determinado momento, normalmente no fim do ano ou de um período prefixado",

Para Coelho e Luiz citados por Bampi (2018, p. 16) dizem que "O balanço sofreu alterações significativas na sua estrutura...”. Entretanto, sua composição é a que está na tabela abaixo. 
Quadro 5 - Balanço Patrimonial

\begin{tabular}{|l|l|}
\hline \multicolumn{1}{|c|}{ ATIVO } & \multicolumn{1}{c|}{ PASSIVO } \\
\hline Circulante & Circulante \\
\hline Não circulante & Não circulante \\
\hline Realizável a longo prazo & Patrimônio líquido \\
\hline Investimentos & \\
\hline Mobilizado & \\
\hline Intangível & \\
\hline
\end{tabular}

Fonte: Coelho e Luiz citados por Bampi (2018, p.16)

Bampi (2018, p.16) mostra que o balanço patrimonial fornece informações sobre bens, direitos e obrigações de uma empresa. Também analisa a estrutura do endividamento da empresa, mostrando as principais fontes de recursos. Mede a capacidade de pagamento de dívidas nos prazos estabelecidos. O capital de giro é representado por todas as contas que constam no ativo e no passivo circulante, pode nos dar essa medida de liquidez da empresa.

A citação acima mostra que o balanço patrimonial é uma ferramenta de gestão, que dá embasamento para que se conheça a posição financeira da empresa, em um determinado período de tempo. Além disso, com a utilização de índices e análises podemos extrair informações sobre a capacidade de pagamento da mesma, fazer comparações com outros exercícios, para verificar a evolução de cada conta. O balanço patrimonial é praticamente a base de todo o processo contábil.

\section{Demonstração do resultado do exercício}

Para Assef (1999, p.93) citado por Henrique (2008, p.40), “a Demonstração de Resultado do Exercício, constitui-se no relatório sucinto das operações realizadas pela empresa, durante determinado período de tempo, no qual sobressai o resultado líquido do exercício, lucro ou prejuízo".

A Demonstração do Resultado do Exercício (DRE), conforme artigo 187, da Lei n. 6.404/76, determina:

I - a receita bruta das vendas e serviços, as deduções das vendas, os abatimentos e os impostos;

II - a receita líquida das vendas e serviços, o custo das mercadorias e serviços vendidos e o lucro bruto;

III - as despesas com as vendas, as despesas financeiras, deduzidas das receitas, as despesas gerais e administrativas, e outras despesas operacionais; 
IV - o lucro ou prejuízo operacional, as outras receitas e as outras despesas;

V - o resultado do exercício antes do Imposto sobre a Renda e a provisão para o imposto;

VI - as participações de debêntures, empregados, administradores e partes beneficiárias, mesmo na forma de instrumentos financeiros, e de instituições ou fundos de assistência ou previdência de empregados, que não se caracterizem como despesa;

VII - o lucro ou prejuízo líquido do exercício e o seu montante por ação do capital social. $\S 1^{\circ} \mathrm{Na}$ determinação do resultado do exercício serão computados: a) as receitas e os rendimentos ganhos no período, independentemente da sua realização em moeda; e b) os custos, despesas, encargos e perdas, pagos ou incorridos, correspondentes a essas receitas e rendimentos (BRASIL, 1976).

Observou-se que o parágrafo $1^{\circ}$ do inciso VII diz que as receitas e os rendimentos ganhos no período, independentemente da sua realização em moeda e os custos, despesas, encargos e perdas, pagos ou incorridos, correspondentes a essas receitas e rendimentos.

Quadro 6 - Exemplo de demonstração de resultado

\begin{tabular}{|l|c|}
\hline \multicolumn{2}{|c|}{ DEMONSTRAÇÃO DE RESULTADO DE UMA EMPRESA (em R\$) } \\
\hline Receita Bruta de Vendas & 486.134 \\
\hline Deduções da Receita Bruta & $(48.613)$ \\
\hline Impostos sobre Vendas & 437.521 \\
\hline \multicolumn{2}{|c|}{} \\
\hline Receita Líquida de Vendas & $(292.759)$ \\
\hline Custo das Mercadorias Vendidas & 144.762 \\
\hline \multicolumn{2}{|c|}{} \\
\hline Lucro Bruto & $(26.235)$ \\
\hline Depreciação & $(14.397)$ \\
\hline Despesas de Vendas & $(33.595)$ \\
\hline Despesas Administrativas & 2.310 \\
\hline Receitas Financeiras & $(18.780)$ \\
\hline Despesas Financeiras & 1.498 \\
\hline Outras Rec. Operacionais & 55.563 \\
\hline \multicolumn{2}{|c|}{} \\
\hline Resultado Operacional & $(19.447)$ \\
\hline Provisão para IR/CSLL & 36.116 \\
\hline Lucro Líquido &
\end{tabular}

Fonte: Henrique $(2008, \mathrm{p}, 41)$

Para Henrique (2008, p.41), a Demonstração do Resultado, bem como as demais demonstrações contábeis são elaboradas de acordo com o princípio de competência. Assim, o empreendedor compreende e avalia todas as variáveis que influenciam o resultado. Como a política de preços, volumes de produção e de vendas, impostos devidos, custos e demais variáveis. 


\section{Demonstração do fluxo de caixa}

De acordo com Caetano (s/d, p.39), a demonstração dos fluxos de caixa fornece informações sobre as alterações no caixa. Para o autor: "[...] evidenciando separadamente as mudanças nas atividades operacionais, nas atividades de investimento e nas atividades de financiamento". As demonstrações do fluxo de caixa são tão importantes que as decisões econômicas que são tomadas pelos usuários exigem avaliação da capacidade de a entidade gerar caixa e equivalentes de caixa, bem como da época de sua ocorrência e do grau de certeza de sua geração.

Abaixo, um exemplo do quadro de fluxo de caixa, mostrado por Henrique (2008)

Quadro 7 - Demonstração de Fluxo de Caixa

\begin{tabular}{|l|l|l|l|l|}
\hline \multirow{2}{*}{ FLUXO DE CAIXA } & \multicolumn{3}{c|}{ PERÍODO } \\
\hline & \multicolumn{2}{|c|}{ Janeiro } & \multicolumn{2}{c|}{ Fevereiro } \\
\hline 1 - Entradas & Previsto & Realizado & Previsto & Realizado \\
\hline Vendas à vista & & & & \\
\hline Vendas a prazo & & & & \\
\hline Outras Receitas & & & & \\
\hline Total de Entradas & & & & \\
\hline 2-Saídas & & & & \\
\hline Compras à vista & & & & \\
\hline Compras a prazo & & & & \\
\hline Impostos & & & & \\
\hline Salários & & & & \\
\hline Outros pagamentos & & & & \\
\hline Total de Saídas & & & & \\
\hline Saldo Inicial & & & & \\
\hline (+) Total de entradas & & & & \\
\hline (-) Total de saídas & & & & \\
\hline (=) Saldo Final & & & & \\
\hline
\end{tabular}

Fonte: Henrique (2008, p.56)

De acordo com Amorim (s/d, p.12), "O gerenciamento condiciona ao controle efetivo de todo tipo de transação da empresa, seja uma venda ou uma aquisição, por exemplo". Assim, por intermédio do gerenciamento contábil o gestor pode acompanhar o desempenho da empresa, a partir de relatórios que servem para apuração adequada de informações. 


\section{Metodologia}

O estudo foi realizado por meio de pesquisa bibliográfica de livros, artigos, monografias, dissertações, teses, sendo possível recolher, ler, selecionar, interpretar e fichar esse material. De acordo com Martins (1994) apud Henrique (2008), a pesquisa descritiva é de fundamental importância num trabalho de base bibliográfica.

O trabalho teve como foco o estudo do funcionamento das demonstrações contábeis (balanço, demonstração do resultado e fluxo de caixa) como ferramentas para a contabilidade gerencial na tomada de decisão dentro das empresas.

\section{Considerações finais}

Observou-se ao longo desse artigo que a contabilidade gerencial é uma grande aliada no Processo de Tomada de decisão. Assim, percebeu-se que ela está diretamente ligada ao planejamento e controle de uma empresa, ambos como instrumentos de administração para os gestores, visando ajudar uma organização a ficar sob controle, identificar quando o processo está fora do controle e dar suporte à aprendizagem da empresa, onde tem como objetivo melhorar a qualidade das operações, reduzir os custos operacionais e aumentar a adequação das operações às necessidades dos clientes.

Ao que se constatou, a contabilidade gerencial usa os recursos da contabilidade financeira para a tomada de decisão, onde, sem esse suporte, não seria possível existir. Ao mesmo tempo esses recursos da contabilidade gerencial, bem organizados pelo gestor, facilita a tomada de decisão, gerenciamento e planejamento.

As ferramentas do Balanço Patrimonial possibilitam uma visão da empresa em seus diferentes aspectos, bem como o resultado do exercício e o fluxo de caixa.

E não se pode negar que os três recursos usados no estudo permitem a elaboração de índices financeiros e econômicos, podendo ser usados por empresários de qualquer tamanho, seja micro, pequeno, médio e grande.

Em resumo. A demonstração do fluxo de caixa serve para o gestor manter o controle da entrada e saída de recursos financeiros, sendo de grande valia para gestões financeiras de curto e de longo prazo.

O planejamento financeiro feito pela contabilidade gerencial só funciona, se tiver um sistema de contabilidade integrado. Assim, com a intensa concorrência e com o mercado em 
constante mutação, o empresário o empresário não pode mais tomar decisões baseadas em experiências que julgar ter. Mas é necessário adequar-se às novas tecnologias, as mudanças impostas pela concorrência, no cotidiano empresarial.

Assim, o empresário deverá cobrar de seu contador maios participação no processo gerencial, fornecendo informações para que a contabilidade gerencial tenha o poder de decisão em cada momento.

Dessa forma, a contabilidade gerencial nas empresas passa a estar sempre presente na tomada de decisão, sendo um suporte a administração segura. Os novos tempos exigem um contador adequado às mudanças ou será defasado, correndo o risco de cair fora do mercado.

\section{Referências}

AMORIM, Diego Felipe Borges de. A importância da contabilidade gerencial para a Gestão dos negócios. Artigo (Consultoria e Planejamento Empresarial). Universidade de Campinas (UCAM).

ASSEF, Roberto. Guia prático de administração financeira: pequenas e médias empresas, Rio de Janeiro: Campus, 1999.

ATKINSON, Anthony A.; BANKER, Rajiv D.; KAPLAN, Robert S.;YOUNG, Mark. Contabilidade gerencial. São Paulo: Atlas, 2000.

BAMPI, Cleber; SILVA, Hermer Antonio Carvalho. A Contabilidade Gerencial como Ferramenta de Gestão em Uma Microempresa de Lucas do Rio Verde: Estudo de Caso da Empresa Lima Felisberto \& Cia Ltda ME. Revista Científica Multidisciplinar Núcleo do Conhecimento. Ano 03, Ed. 05, Vol. 01, pp. 107-146, Maio de 2018. ISSN:2448-0959

BRASIL (1976) Lei n. 604, de 15 de dezembro de 1976. Presidência da República. Casa Civil. 1976.

CETANO, Paulo (Presi.). Conselho Regional de Contabilidade do Paraná. Demonstrações Contábeis - Aspectos Práticos - Elaboração e Apresentação conceitual de acordo com o IFRS. Curitiba-PR- sem data.

CREPALDI, Silvio Aparecido, Contabilidade Gerencial, 4 ed. São Paulo: Atlas 2008, p.5.) citado por AMORIM, Diego Felipe Borges de. A importância da contabilidade gerencial para a Gestão dos negócios. Artigo (Consultoria e Planejamento Empresarial). Universidade de Campinas (UCAM).

CREPALDI, Silvio Aparecido. Contabilidade Gerencial, 4 ed. São Paulo: Atlas 2008.

DAUZACKER, Nilson. Estudo sobre a utilização da Contabilidade Gerencial em empresas com serviços contábeis terceirizados. Revista de Estudos Sociais Ano 4 n.7 2002 ,77-95 
FREZATTI, Fábio; GUERREIRO, Reinaldo; AGUIAR, Andson Braga de; GOUVÊA, Maria Aparecida. Análise do relacionamento entre a contabilidade gerencial e o processo de planejamento das organizações brasileiras. Rev. adm. contemp. vol.11 no.spe2 Curitiba 2007. Disponível em: < http://www.scielo.br/scielo.php?script=sci_arttext\&pid=S1415$65552007000600003>$ Acesso em 24.set.2018

HENRIQUE, Marco Antônio. A importância da contabilidade gerencial para micro e pequena empresa. Monografia. (Mestrado) Universidade de Taubaté. SP- 2008

IUDÍCIBUS, Sergio de. Contabilidade gerencial, 4.ed. São Paulo: Atlas,1986.

5. ed. São Paulo: Atlas, 1995, p.21) citado por DAUZACKER, Nilson. Estudo sobre a utilização da Contabilidade Gerencial em empresas com serviços contábeis terceirizados. Revista de Estudos Sociais Ano 4 n.7 $2002,77-95$

Contabilidade Gerencial. 5. ed. São Paulo: Atlas, 1995.

Teoria da Contabilidade. 7a edição. São Paulo: Atlas, 2005

Teoria da Contabilidade. 7a edição. São Paulo: Atlas, 2005). Citado por AMORIM, Diego Felipe Borges de. A importância da contabilidade gerencial para a Gestão dos negócios. Artigo (Consultoria e Planejamento Empresarial). Universidade de Campinas (UCAM).

JUNQUILHO, Gelson Silva. Gestão e ação gerencial nas organizações contemporâneas - para além do folclore e o fato. Gestão \& Produção v.8. n.3, p.304-318.. 2001. Disponível em:< http://www.scielo.br/pdf/gp/v8n3/v8n3a07.pdf > Acesso em 23.set.2018

KASSAI, Silvia. As Empresas de Pequeno Porte e a Contabilidade. Caderno de Estudos, São Paulo, FIPECAFI, v.9, n.15, p.60-74, janeiro-junho 1997

MACHADO, Janaina Resende; RAPÉ, Sara Ferreira De Lima; SOUZA, Sinvales Roberto Contabilidade gerencial e sua importância para a gestão e tomada de decisão das empresas contemporâneas. Universidade CESUFOZ. Foz do Iguaçu-PR.

MARTINS, Gilberto de Andrade. Manual para a elaboração de monografias e dissertações. 2.ed. São Paulo: Atlas, 1994.

PADOVEZE, Clovis Luis. Contabilidade Gerencial. Curitiba: IESDE, 2012

.O papel da contabilidade gerencial no processo empresarial de criação det valor. Caderno de Estudos, São Paulo, no 21 - Maio a Agosto de 1999 Disponivel em < http://www.scielo.br/pdf/cest/n21/n21a03.pdf > Acesso em 30.set.2018

Sá, Carlos Alexandre, Fluxo de Caixa, 2 ed. São Paulo: Atlas 2008.

SALES, Albaniza Irani. Administração e RH. DataSul Cursos Profissionalizantes, 2007. Disponível em <http://www.cairu.br/biblioteca/arquivos/Administracao/Administracao _RH_Modulo_I.pdf > Acesso em 24.set.2018 
SEBRAE. Serviço Brasileiro de Apoio às Micro e Pequenas Empresas. 2011. Disponível em <http://www.sebrae.com.br/uf/goias/indicadores-das-mpe/classificacao-empresarial $>$ Acesso em: 20 de agosto de 2018.

UNILEÃO. Manual para elaboração de trabalhos acadêmicos - Pós graduação.

\section{Como citar este artigo (Formato ABNT):}

MORAIS, Rosa Amélia Carvalho; BARRETO JÚNIOR, Agenor Campos. A Importância da Contabilidade Gerencial para Microempresas e Empresa de Pequeno Porte. Id on Line Rev.Mult. Psic., 2019, vol.13, n.43, p. 903-921. ISSN: 1981-1179.

Recebido: 01/12/2018;

Aceito: 03/12/2018 